\title{
Percepções dos enfermeiros de campo sobre o estágio curricular da graduação de enfermagem realizados em sua unidade de trabalho
}

\author{
PERCEPTIONS OF THE FIELD NURSES ON THE CURRICULAR ASSISTANTSHIP OF THE \\ UNDERGRADUATE COURSE OF NURSING CARRIED OUT IN THEIR WORK UNIT
}

\section{PERCEPCIONES DE LOS ENFERMEROS DE CAMPO SOBRE LAS PRÁCTICAS \\ DEL PRE GRADO DE ENFERMERÍA REALIZADOS EN SU UNIDAD DE TRABAJO}

\author{
Elaine Emi Ito', Regina Toshie Takahashi²
}

Trata-se de um estudo para elaboração de dissertação de mestrado que tem como tema central a percepção dos enfermeiros de campo sobre os estágios curriculares desenvolvidos em sua unidade de trabalho, focalizando o seu papel na formação dos alunos de graduação em Enfermagem.

A pesquisa tem como objetivos: conhecer a percepção dos enfermeiros em relação ao seu papel na formação dos alunos em estágio curricular de Enfermagem; conhecer a influência que os alunos trazem para a unidade; identificar os fatores facilitadores e dificultadores das atividades do enfermeiro com a presença do aluno; conhecer a percepção dos enfermeiros de campo em relação a estrutura do estágio e sugestões de melhoria para o desenvolvimento desta disciplina; e identificar nos enfermeiros que recebem os alunos em suas unidades de trabalho a questão do gostar e de sentir-se preparado para recebe-los em estágio.

No estudo, denominamos o estágio curricular como o último estágio que o aluno realiza no seu curso de graduação. É realizado no último semestre do curso, possui uma carga horária total de 500 horas e tem o acompanhamento a distância do professor responsável, o aluno fica em contato direto e constante com o enfermeiro de campo na unidade a qual realiza o estágio curricular.

Diversos autores apontam a importância dos estágios na formação profissional e pessoal dos profissionais de Enfermagem para o desenvolvimento de atitudes, comportamentos e habilidades, para a interação com a equipe multiprofissional de saúde, familiares e pacientes e, principalmente, para a possibilidade de analisar crítica e reflexivamente as interfaces do conhecimento teórico e prático ${ }^{(1-4)}$.

O enfermeiro atuante na prática tem papel fundamental no processo de aprendizagem do aluno que desenvolve o estágio curricular em sua unidade de trabalho, pois será uma referência importante de trabalho, o facilitador e o intermediador da integração do aluno ao serviço e a equipe de saúde; muitas vezes, o exemplo do profissional enfermeiro, e para tanto, é necessário que esteja preparado e seguro para transmitir a sua experiência, a qual permitirá ao aluno assimilar os conhecimentos teóricos adquiridos em sala de aula com a prática que está sendo vivenciada em campo de estágio ${ }^{(3)}$.

Visto que o estágio é um momento de suma importância no processo de formação profissional e pessoal do aluno de Enfermagem e que o enfermeiro atuante no campo da prática tem significativa influência no desenvolvimento de habilidades, técnicas e atitudes do estagiário de Enfermagem, e percebendo, após a exploração de materiais de pesquisa e estudo sobre o tema, a quantidade escassa de materiais referente a percepção dos enfermeiros de campo na formação dos alunos de graduação em estágios, acredito que esta pesquisa possa contribuir para melhoria no desenvolvimento dos estágios curriculares e na formação do enfermeiro.

Atualmente, estou na função de enfermeira do Serviço de Educação Continuada de uma Instituição reconhecida como Hospital de Ensino, que oferece campo de estágios a alunos de Enfermagem e de outras áreas da saúde. Considero que a responsabilidade da qualidade da formação dos enfermei-
1 Enfermeira do Serviço de Educação Continuada do Hospital Santa Marcelina Especialista em Adminis tração de Serviços de Saúde. Mestranda pela Escola de Enfermagem da USP (EEUSP). emi.ito@uol.com.br

2 Enfermeira. Professora Doutora do Departamento de Orientação Profissional da EEUSP. Orientadora do trabalho.
Recebido: 15/10/2004

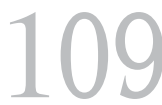

Rev Esc Enferm USP 2005; 39(1):109-10. 
Elaine Emi lto

Regina Toshie Takahashi ros e profissionais de Enfermagem não é só dos órgãos formadores, mas também das instituições de ensino prestadoras de assistência à saúde e, principalmente, do profissional enfermeiro envolvido no desenvolvimento do estágio em sua unidade de trabalho.

Com relação ao delineamento metodológico, trata-se de um estudo exploratório, descritivo e com abordagem qualitativa. A pesquisa será desenvolvida em uma instituição hospitalar caracterizada como hospital de ensino, filantrópico, geral, localizado no município de São Paulo. Serão sujeitos do estudo enfermeiros assistenciais que receberam alunos em estágio curricular dentro de sua unidade de trabalho. A coleta de dados será através da técnica de entrevista semi-estruturada. A entrevista será gravada e os gravados serão transcritos na íntegra, permitindo assim uma leitura fluente dos depoimentos. A referência para a análise dos depoimentos constituir-se-á na análise de conteúdo, definida como:

Um conjunto de técnicas de análise das comunicações visando obter, por procedimentos, sistemáticos e objetivos de descrição do conteúdo das mensagens, indicadores (quantitativos ou não) que permitam a inferência de conhecimentos relativos às condições de produção/ recepção (variáveis inferidas) destas mensagens ${ }^{(5)}$.

\section{REFERÊNCIAS}

(1) Tetila ZF. Estágio supervisionado: diagnóstico de proposta de reformulação para os cursos do Centro Universitário de Dourados UFMS. [dissertação] São Paulo (SP): Pontifícia Universidade Católica de São Paulo; 1984.

(2) Andrade MN, Araújo LCA, Lins LCS, Lins LCS. Estágio curricular: avaliação de experiência. Rev Bras Enferm $1989 ; 42(1 / 4): 27-41$

(3) Bousso RS, Merighi MABM, Rolim MA, Riesco MLG, Angelo M. Estágio curricular em enfermagem: transição de identidades. Rev Esc Enferm USP 2000; 34(2):218-25.

(4) Valsecchi EASS, Nogueira MS. Fundamentos de enfermagem: incidentes críticos relacionados à prestação de assistência em estágio supervisionado. Rev Lat Am Enferm 2002; 10(6): 19-24.

(5) Bardin L. Análise de conteúdo. Lisboa: Edições 70; 1977.
Correspondência:

Elaine Emi Ito

Rua Brígida de

Vasconcelos, 62

São Paulo

CEP: 08290-650 - SP

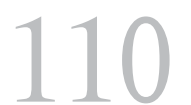

Rev Esc Enferm USP 2005; 39(1):109-10. 